\title{
Development of foraging strategies with age in a long-lived marine predator
}

\author{
Greg A. Breed ${ }^{1,3, *}$, W. Don Bowen ${ }^{2}$, Marty L. Leonard ${ }^{1}$ \\ ${ }^{1}$ Department of Biology, Dalhousie University, 1355 Oxford Street, Halifax, Nova Scotia B3H 4J1, Canada \\ ${ }^{2}$ Bedford Institute of Oceanography, 1 Challenger Drive, Dartmouth, Nova Scotia, B2Y 4A2, Canada \\ ${ }^{3}$ Present address: Harvard Forest, Harvard University, 324 North Main Street, Petersham, Massachusetts 01366, USA
}

\begin{abstract}
The development of foraging strategies as animals mature depends upon experience, stage-specific physiology, the onset of reproductive maturity and the reproductive costs incurred by each sex. To understand the ontogeny of foraging behaviour, we compared movement behaviour of 24 young-of-year (YOY) juveniles (12 male, 12 female) with 6 subadult (4 male, 2 female) and 81 adult (43 male, 38 female) grey seals Halichoerus grypus. We used a behaviour discriminating state-space model followed by a series of mixed-effects models to examine trip structure and habitat use in these age classes. In foraging trips, tortuosity and speed of outbound travel were not different in YOY, subadults and adults, suggesting that YOY navigate as well as older animals. On average, however, YOY trips lasted 1.2 to $3.5 \mathrm{~d}$ longer and required up to twice as much transit time to reach foraging areas that were 1.5 to 3 times farther from haul-out sites than those of subadults and adults. This suggests an overall apparent higher foraging effort for YOY. Differences, however, were highly seasonally dependent. In all groups, apparent foraging effort decreased in the summer and increased in the winter, which is consistent with seasonal changes in prey distribution and energy content. Adult foraging patterns showed complex seasonal patterns influenced by both reproductive cycles and seasonal environmental variation, whereas annual foraging patterns of YOY and subadults, neither of which invest in reproduction, were simpler and appeared more closely tied to seasonal changes in prey availability and condition. Although foraging in the same habitats, male and female YOY showed small but significant differences in movement behaviour and trip structure. These differences are unlikely to be due to size difference, which is minimal at this age, and suggest that sex-related differences in foraging develop early before sexual size dimorphism is significantly expressed.
\end{abstract}

KEY WORDS: Animal movement · Ontogeny · Juvenile foraging $\cdot$ Foraging strategy $\cdot$ Optimal annual routine $\cdot$ Sexual segregation $\cdot$ Marine mammal

\section{INTRODUCTION}

The idea of a behavioural 'strategy' is an abstract construction that allows biologists to think about how an animal's behavioural repertoire affects its fitness and life history. Strategies are not conscious processes and are never implemented perfectly; they are an emergent phenomenon formed by the collection of behaviours expressed by an individual and shaped by natural selection and evolution.
Many behaviours can be governed by strategies, but central to an animal's overall fitness is its foraging strategy (Stephens \& Krebs 1986). Animals can use a single foraging strategy their whole life or switch among strategies as conditions change. Foraging strategies are often size- and age dependent, and are highly influenced by reproductive state and sex (McNamara \& Houston 1986, Stephens \& Krebs 1986). They are also influenced by environment, which usually varies on multiple time scales, including daily, sea- 
sonally, annually, inter-annually and across decades. Where seasonal variation in food resources is high and predictable, animals should change their foraging strategies over the course of the year, and seasonal foraging strategies should be nested in a larger overarching annual strategy or routine (McNamara \& Houston 2008).

The annual strategy is also likely to be strongly influenced by the animals' condition and reproductive status, age and ontogeny, with sexually immature individuals potentially expressing very different routines than adults. When attempting to understand how juvenile foraging strategies develop, differences in behaviour caused by age, sex, size, and reproductive status can be mistaken for seasonal changes in behaviour caused by annual environmental variation. These factors must be disentangled from each other in order to understand the ontogeny of foraging behaviour. Such a study would require, at the very least, year-long behavioural observations across all representative age and sex classes. Observations from species in which the vertical transmission of foraging skills from parent to offspring does not occur would further simplify the problem.

Seals are excellent models for studying the development of foraging strategies, despite the general difficulties of observing marine animals at sea. Juveniles are large and robust and so can carry their own electronic observation equipment for many months, providing long and uninterrupted behavioural records (McConnell et al. 2002, Raum-Suryan et al. 2004, Field et al. 2005, Baker 2007). Most true seals (Phocidae) become independent before they begin foraging, so the influence of parents on the development of foraging skills does not complicate the developmental process. In many other mammals and birds, juveniles become independent gradually, become unobservable because they disperse away from parents (and observing researchers) at the moment of independence, or remain in mixed-age social groups where juvenile foraging is never independent of adults (Marchetti \& Price 1989, Clutton-Brock \& Godfray 1991, Heinsohn 1991).

To that end, we set out to understand the development of annual patterns of foraging and movement in young-of-the-year (YOY) grey seals Halichoerus grypus. To do this, we compared their annual routines with those of older but still pre-reproductive subadults and reproductive adults. Individuals from our study population breed on Sable Island, Nova Scotia. They forage primarily on the Scotian Shelf, a broad, shallow ocean margin off Canada's east coast characterised by complex glacially altered bathymetry and an ecosystem that has been highly disturbed by overfishing (Frank et al. 2005). This region is temperate at $44^{\circ} \mathrm{N}$ and, typical of temperate oceans, has strong annual cycles of ocean productivity and temperature, major annual fish migrations (which affects prey availability) and strong seasonal changes in fish condition (which affects prey quality) (Perry \& Smith 1994, Swain et al. 1998, Comeau et al. 2002). Seasonality in foraging behaviour has been detected in adults from this population (Beck et al. 2003a, Austin et al. 2006, Breed et al. $2006,2009)$. As such, we expected to find a strong seasonal component in the foraging behaviour of adults in order to time foraging effort to annual breeding events. We also expected to find seasonal patterns in younger age classes. However, the pre-reproductive status of YOY and subadults should cause them to organise annual strategies differently than adults, and strategies should be more closely tied to prey availability or other external cues.

In addition to understanding state-specific annual foraging patterns in juveniles, we investigated the development of sex-specific foraging patterns. Previous studies have demonstrated marked sex-related differences in the foraging behaviour of adult grey seals (Beck et al. 2003c, 2007, Breed et al. 2006, 2009). In other sexual size-dimorphic species, sex-specific foraging behaviours are often thought to result from allometric differences caused by the size differential between the sexes (Ruckstuhl \& Neuhaus 2005). If sexrelated differences in foraging are detected in YOY, which are not strongly size dimorphic, it would suggest that these differences are not due only to size, but begin very early in life and to some degree are ontogenetically controlled. Such early behavioural differentiation has been suspected in other sexually sizedimorphic species, but has been extremely difficult to demonstrate (Ruckstuhl \& Neuhaus 2005). Taken together, the differences we found between the sexes, among reproductive and pre-reproductive age classes, and through the annual foraging cycle allow us to clearly understand the development of foraging strategies and the influence of reproductive state and age, and disentangle environmental from ontogenetic factors controlling annual foraging strategies in this major marine predator.

\section{MATERIALS AND METHODS}

Data collection. In late May 2004, 24 (12 male, 12 female) YOY grey seals were captured on Sable Island, Nova Scotia $\left(44.0^{\circ} \mathrm{N}, 60.0^{\circ} \mathrm{W}\right.$; Fig. 1a). YOY were 5 mo old when tagged to avoid losing a large fraction of our sample early in the study, as mortality of newly weaned pups can approach $30 \%$ (Schwarz \& Stobo 2000).

YOY were captured with hand-held nets, weighed and anesthetised with Telazol. The average dose re- 

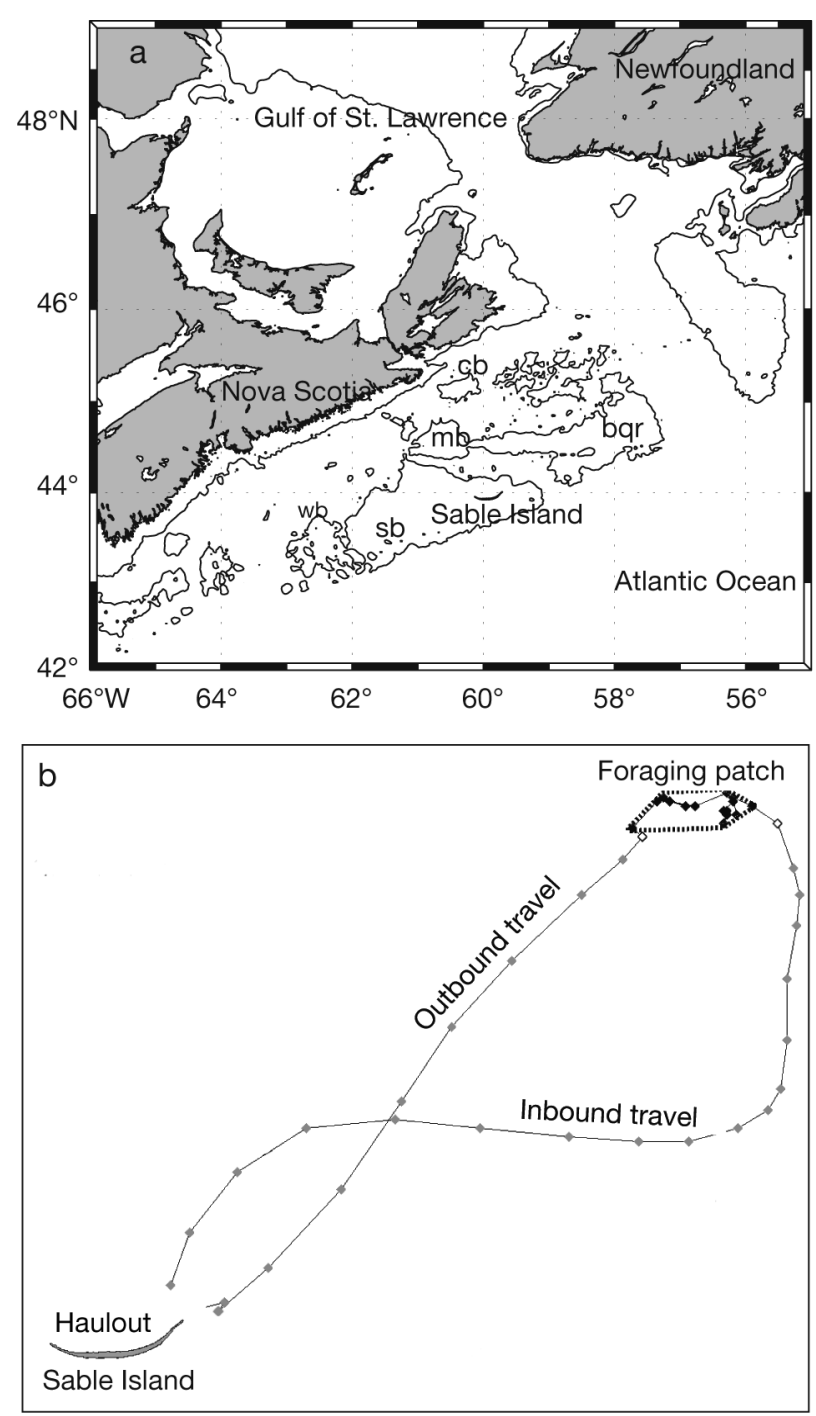

Fig. 1. (a) Study area showing Sable Island and prominent banks. bqr: Banquereau; cb: Canso Bank; mb: Middle Bank; sb: Sable Bank; wb: Western Bank. Contour line is the $100 \mathrm{~m}$ isobath. (b) Trips were divided into segments using statespace model behavioural state estimates. Grey points indicate travel, black points indicate foraging and open points indicate uncertain behaviour (from Breed et al. 2009) quired for safe immobilisation was $0.94 \mathrm{mg} \mathrm{kg}^{-1}$ (SE = 0.13), near the standard dose for adult females (1 $\mathrm{mg}$ $\mathrm{kg}^{-1}$; Austin et al. 2003). While animals were anaesthetised, Argos satellite transmitters (model SRDL 7000, Sea Mammal Research Unit, St. Andrews, UK, weighing $370 \mathrm{~g}$ ) were affixed to the neck just behind the cranium using 5-minute epoxy (Austin et al. 2003). Tags were left on until they fell off with the moult in March or April 2005, although most tags stopped transmitting before that time (20 tags lasted until 1 September 2004, 14 until 1 January 2005 and 9 until 1 March 2005). Transmitters provided between 5 and 15 locations per day. In addition to YOY, 6 subadults (2-3 yr old; 4 male, 2 female) and 15 adults ( 7 male, 8 female) were tagged at the same time using the same tag model and attachment methods. The adults became part of a larger data set that included a total of 81 individuals tagged in small numbers between 1995 and 2005, allowing for comparison of YOY, subadult and adult behaviour (Table 1). Our data are not observations of foraging per se. However, as foraging is essentially the only reason seals make trips to sea, we can infer that any patterns found in movement are directly related to foraging behaviour.

State-space model. A state-space model (SSM) was used to model Argos tracking data. Argos satellite transmitters report locations at irregular time intervals and with considerable error (Vincent et al. 2002, Jonsen et al. 2005, Service Argos 2009). The SSM was used to handle observation error and infer behaviour, producing regular location estimates with inferred behavioural states (Jonsen et al. 2005, Patterson et al. 2008, Schick et al. 2008).

We used the same behaviour-switching SSM as Breed et al. (2009) to model movement tracks. The process model uses the correlation and turn angle between consecutive locations to estimate a best location from the data and groups movement into 2 categories based on those model fit correlation and turn angle parameters. The 'foraging' state is comprised of motion that produces high turn angles and low autocorrelation between consecutive displacements. This behaviour resulted in animals remaining in small areas for extended periods. 'Travel' included high autocorrelation between consecutive displacements with small turn angles, producing linear movement that moved animals quickly between distant locations. The observation model fit Argos locations to a t-distribution with 6 variance classes, one for each Argos location class, and the predictions from the process model

were integrated with the observa-
Table 1. Halichoerus grypus. Sample sizes for young-of-the-year (YOY), subadult and adult grey seals for the trip analysis during each season, and total sample size. The number of animals tracked is shown first; the number of trips made by those animals is in parentheses. Animals whose tracks spanned more than 1 season wer counted in each season the track spanned. Adults were tagged between 1996 and 2004, whereas YOY and subadults were tagged in 2004

\begin{tabular}{|lcccccccccc|}
\hline & \multicolumn{3}{c}{ Winter } & & \multicolumn{3}{c}{ Summer } & & \multicolumn{3}{c|}{ Fall } & & & \multirow{2}{*}{ Total } \\
& Male & Female & Male & Female & Male & Female & & Male & Female \\
\hline Adult & $16(62)$ & $17(67)$ & $16(84)$ & $14(86)$ & $32(156)$ & $31(186)$ & $43(302)$ & $38(337)$ \\
YOY & $5(13)$ & $7(20)$ & $12(90)$ & $12(88)$ & $9(68)$ & $10(93)$ & $12(164)$ & $12(159)$ \\
Subadult & $4(16)$ & $1(4)$ & $4(35)$ & $4(51)$ & $4(51)$ & $2(20)$ & $4(102)$ & $2(39)$ \\
\hline
\end{tabular}


tions using a Bayesian Markov chain Monte Carlo (MCMC) method in the software package WinBUGS. An extensive description of the model as well as a supplement containing working model code are available in Breed et al. (2009).

Trip analysis. Many marine mammals and birds organise foraging into trips at sea punctuated by periods ashore. In grey seals, foraging trips last between 1 and $30 \mathrm{~d}$ and usually consist of 3 clear segments. The first is an outbound period of rapid and direct travel between haul-out and foraging areas. This is usually followed by a period spent foraging. Finally, a period of directed travel returns the animal to a haul-out site. Not all trips fit this pattern; some include apparent travel segments between multiple foraging areas, some do not include apparent foraging and some do not include apparent travel.

SSM fits produced location estimates at regular $8 \mathrm{~h}$ intervals and an estimate of behavioural state at each location. Eight hours is the smallest time step we could use given the temporal resolution of the Argos data being fit (see Breed et al. 2009, 2011). As in other implementations of this model, the proportion of MCMC samples in each respective behavioural state was used to classify behaviour, with proportions above 0.7 assigned to travel, proportions below 0.3 assigned to foraging and intermediate proportions assigned as uncertain (Jonsen et al. 2007, Breed et al. 2009). In practice, the uncertain behavioural state tended to show some autocorrelation between consecutive steps, so for the trip analyses undetermined locations were included in travel segments. The results were then used to discriminate trips and trip segments objectively using changes in inferred behavioural state detected by the SSM.

We defined trips such that they began only when an animal moved more than $2 \mathrm{~km}$ from any shoreline and ended when the animal returned to within $2 \mathrm{~km}$ of land. In addition, to be considered a trip, animals had to spend at least $1 \mathrm{~d}$ (3 consecutive locations) at least $2 \mathrm{~km}$ from shore. Defining trips this way was necessary because the spatial and temporal resolution of Argos location data made it difficult to resolve shorter trips, even after fitting with SSMs. Finally, trips that began at Sable Island and ended elsewhere (or vice versa) were not included because they were rare (less than $1 \%$ ) and because part or all of the trip was migratory in nature.

Once trips were identified, trip segments were determined using the behavioural categorisation of the SSM (Fig. 1b). During trips, whenever behaviour switched to, and remained in, the foraging state for at least 3 consecutive locations (at least $1 \mathrm{~d}$ ), those foraging locations were considered a discrete foraging area, and the length of time spent in that area was defined as patch residence time. Most trips had just one foraging patch, and the subsequent travel segment usually returned the animal to haul-out, but if not, additional foraging and travel segments were discriminated the same way.

Seven trip characteristics were analysed for comparison between age classes: trip duration, patch residence, patch distance from haul-out, foraging ratio, travel time, travel speed and travel tortuosity. Trip duration and patch residence time are straightforward measures of trip properties. The other 5 measures were defined as follows. Patch distance is the distance from the centroid of each foraging area to the haul-out location from which the trip originated. Foraging ratio is the fraction of SSM location estimates categorised as foraging divided by the total number of SSM location estimates in the trip. Recalling that location estimates are evenly spaced in time, this relates directly to the fraction of time spent foraging. Travel time is the time spent in the travel state between leaving haul-out sites and entering the foraging state. Travel speed and travel tortuosity were calculated only for the first travel segment, and only for trips with outbound travel segments of at least $1 \mathrm{~d}$. Travel speed is the sum of distances between locations in the outbound travel segment divided by travel time. Finally, travel tortuosity was calculated from the sum of distances between locations in the outbound travel segment divided by the patch distance. A travel tortuosity of 1 means travel distance is exactly the same as patch distance and therefore travel was perfectly direct; increasing values indicate less direct travel.

These characteristics were chosen because they were relatively easy to measure and could be related to navigation, foraging effort and many well-established aspects of foraging theory (Stephens \& Krebs 1986, Zollner \& Lima 1999). Five of the characteristics can be considered proxies for effort: trip length, patch distance, travel time, patch residence and foraging ratio. Tortuosity and, to a lesser extent, travel speed can be considered proxies for navigation if we assume that animals travelling faster and more directly to foraging patches are better navigators.

To characterise habitat, 2 habitat properties at SSMinferred foraging locations were also analysed: distance from the nearest shoreline and water depth. Distance from shore may be important because many prey species have a seasonal migration which brings them inshore in summer and offshore in winter (Perry \& Smith 1994). Since grey seals are benthic foragers and there is evidence that bottom depth is an important habitat constraint (Austin et al. 2006), water depth was extracted at SSM location estimates from a bathymetric grid (Sandwell \& Smith 1992; 3 km spatial resolution).

Mixed-effects models. To assess differences in trip characteristics and habitat use, as well as understand 
seasonal patterns and account for individual random effects and autocorrelation, we formulated a series of generalised linear mixed-effects models. Models were fit to SSM output (location and behavioural state estimates) using the 'lme' function (included in the nlme package; Pinheiro et al. 2009) within the freely available software environment R ( $\mathrm{R}$ Development Core Team 2008).

Trip and habitat properties were positive and right skewed or ratios. To accommodate this, trip properties were log transformed and ratios were logit transformed. Because neither of these transformations can accommodate zeros, $4 \mathrm{~h}$ were added to travel time values of 0 , corresponding to one-half our unit of measurement of 1 location every $8 \mathrm{~h}$, and 0.001 was added to foraging ratios of 0 and subtracted from foraging ratios of 1 . This approach was appropriate as log and logit transformations produced residuals that were normally distributed when plotted against model-fitted values for all models.

The basic structure of mixed-effects models used here included 1 random and 2 fixed effects, plus interaction terms. Individual was included as the random effect. The first fixed effect was demographic group, of which there were initially two, male and female YOY. Masses of YOY were also initially included as a fixed effect. We did find some sex differences between male and female YOY, but they were small, and mass did not explain behaviour (see 'Results'). Consequently, YOY data were merged into a single group, and mass was dropped from analyses comparing YOY with subadult and adult data in order to build a larger sample size for YOY. Male and female adults were treated as separate groups as they are known to have considerable sex-related differences in movement (Austin et al. 2004, Breed et al. 2006, 2009). There were only 6 subadults, most of them males, and they were treated as a single group. Therefore, final mixed-effects models tested for differences in trip and habitat properties among 4 demographic groups: YOY, subadults, adult males and adult females.

In previous studies of NW Atlantic grey seals, seasonality has been treated by reducing time to a categorical variable of month or season (Beck et al. 2003a,c, 2007, Breed et al. 2006, 2009). Initially, we followed this convention, modelling seasons as a 3 group categorical variable (summer $=$ June-September, fall $=$ October-December, winter = January-April). We also modelled season with orthogonal cubic polynomials. However, in order to capture more subtle and complex behavioural effects not possible when imposing fixed time categories or using polynomials, we modelled season using mixtures of sine and cosine waves, which were mapped onto yearday (numerical day of the year from 1 to 365.25 ) using the functions:

$$
\begin{aligned}
\alpha_{\sin _{f}} & =\sin \left(\frac{f \times \text { yearday } \times 2 \pi}{365.25}\right) \\
\alpha_{\cos _{f}} & =\cos \left(\frac{f \times \text { yearday } \times 2 \pi}{365.25}\right)
\end{aligned}
$$

where $f$ is frequency, the number of cycles per year and year-day is the day of the year on which any given trip or habitat measure occurred. When $f=1$, for example, these functions produce single sine and cosine waves through the year to which the trip or foraging location properties can be fit (the $\alpha$ 's become explanatory variables). Adding sine and cosine waves together allows the phase to shift to any day of the year. If we were to fit the $f=1$ waves as a simple linear fit to day length, it would fit perfectly with the phase aligned to the solstices. Since change in solar irradiation through the year physically forces virtually all seasonal environmental changes and greatly influences animal behaviour, the phase and amplitude of this sine wave can be directly interpreted when fit to various behavioural traits as related to some observed or unobserved annual seasonal cycle. Frequencies of 2, 3 and 4 were also mapped to year-day to account for higher frequency variation in behaviour. Seasonal patterns are driven by solar irradiance on a sine wave, and primary and secondary production will reflect this cycle but with lag and complication due to the time it takes that energy to move through ecosystems. For example, fish condition strongly follows a sinusoidal annual cycle (see Fig. 9 in Comeau et al. 2002). The cycle of fish condition, however, is offset from primary production and water temperature, as well as the reproductive cycle of grey seals. The multiple frequencies gave the model flexibility to fit these myriad cycles that may be influencing foraging behaviour in a manner similar to a generalised additive model (GAM). However, the sine waves would retain biological relevance where a GAM would not, and the fits of sine and cosine functions to behaviour can be directly interpreted via Akaike's information criterion (AIC) scores.

In total, we fit 4 models using sine functions; the seasonal components of each were as follows:

$$
\begin{array}{ll}
f_{1} & \sim \alpha_{\sin _{1}}+\alpha_{\cos _{1}} \\
f_{1+2} & \sim \alpha_{\sin _{1}}+\alpha_{\cos _{1}}+\alpha_{\sin _{2}}+\alpha_{\cos _{2}} \\
f_{1+2+3} & \sim \alpha_{\sin _{1}}+\alpha_{\cos _{1}}+\alpha_{\sin _{2}}+\alpha_{\cos _{2}}+\alpha_{\sin _{3}}+\alpha_{\cos 3} \\
f_{1+2+3+4} & \sim \alpha_{\sin _{1}}+\alpha_{\cos _{1}}+\alpha_{\sin _{2}}+\alpha_{\cos _{2}}+\alpha_{\sin _{3}}+\alpha_{\cos 3} \\
& +\alpha_{\sin 4}+\alpha_{\cos _{4}}
\end{array}
$$

In addition, each of the year-day mapped trigonometric variables (Eq. 3) included an interaction with the demographic group term, so that seasonality could 
be compared among the 4 groups. For example, a complete model including 2 seasonal frequencies $\left(f_{1+2}\right)$ is expressed as:

$$
\begin{aligned}
& \log (\text { response })= \beta_{0}+\beta_{1} G+\beta_{1} \alpha_{\sin _{1}}+\beta_{3} \alpha_{\cos _{1}}+\beta_{4} \alpha_{\sin _{2}}+ \\
& \beta_{5} \alpha_{\cos _{2}}+\beta_{6} G^{\prime} \alpha_{\sin _{1}}+\beta_{7} G^{\prime} \alpha_{\cos _{2}}+ \\
& \beta_{8} G^{\prime} \alpha_{\sin _{2}}+\beta_{9} G^{\prime} \alpha_{\cos _{2}}+\varphi+b_{i}+\varepsilon_{i, \text { seal }} \\
& b_{i} \sim N\left(0 ; \sigma_{b}^{2}\right), \varepsilon_{i, \text { seal }} \sim N\left(0 ; \sigma^{2}\right)
\end{aligned}
$$

where 'response' is one of the 7 trip or 2 habitat characteristics listed earlier, $G$ is the demographic group (adult females were the base group), $\varphi$ is the $\operatorname{AR}(1)$ autocorrelation coefficient to accommodate behavioural persistence, $b_{i}$ and $\varepsilon_{i \text {, seal }}$ are the between- and within-subject random effects, respectively, primes indicate interaction terms and $\beta$ 's are the model-estimated coefficient for each effect. The interaction terms were demographic group interacting with up to 8 sine and/or cosine transforms from yearday as described in Eqs (1) and (2).

AIC was used to determine the relative support among the 6 different models. After some preliminary analysis, we suspected less complex seasonal cycles for non-reproductive individuals. In order to better understand how models were fitting to different demographic groups, AIC was calculated for models fit individually to YOY and adult data. This allowed AIC scores for each group to be calculated and we were able to assess how these group-specific AIC scores changed with increasing model complexity. Significance was calculated using Wald tests (Harrell 2001), used to detect differences between model coefficients and was corrected using the Holm-Bonferroni method (Holm 1979).

\section{RESULTS}

\section{General model performance for YOY and subadults}

The switching SSM detected 'travelling' and 'foraging' in all tracks (Fig. 2), and SSM parameter estimates were similar to those of adults as reported in Breed et al. (2009) (Table S1 in the supplement at www.int-res.com/articles/suppl/m431p267_supp.pdf). Over all YOY tracks, 59 and $32 \%$ of locations were inferred as foraging and travelling, respectively (Table S2 in the supplement); for subadults this was 65.8 and $25.3 \%$ (Table S3 in the supplement). Although male and female YOY movement was generally similar, there were some significant differences in behaviour. At any given time, female YOY were significantly more likely to be in the foraging state than male YOY (66.2\% of at-sea locations were inferred as foraging in females versus $51.9 \%$ for males; $p=0.008$, Table S3 in the supplement). In the mixed-effect models, mean behavioural traits did not differ significantly between male and female YOY, but there were some significant sex by season interactions (Fig. 3, Table S4 in the supplement). In particular, male YOY foraged in significantly deeper water than females during the summer $(39.8 \pm 4.5 \mathrm{~m}$ for males vs. $32.8 \pm 4.8 \mathrm{~m}$ for females, $\mathrm{p}<0.0001$ ), and female YOY remained in foraging patches significantly longer than males during the winter $(1.5 \pm 0.5 \mathrm{~d}$ for males vs. $4.7 \pm 2.1 \mathrm{~d}$ for females, $\mathrm{p}=0.003)$. Male YOY outweighed females at deployment by approximately $9 \%$ (39.6 \pm 4.7 and $36.4 \pm$ $5.2 \mathrm{~kg}$, respectively, $\mathrm{p}=0.12$ ) but the difference was not significant, and mass explained no behavioural property in YOY. The above differences are biologically interesting, but small. Consequently, in all subsequent analyses, YOY were treated as a single group to increase sample size for comparison against older age classes.
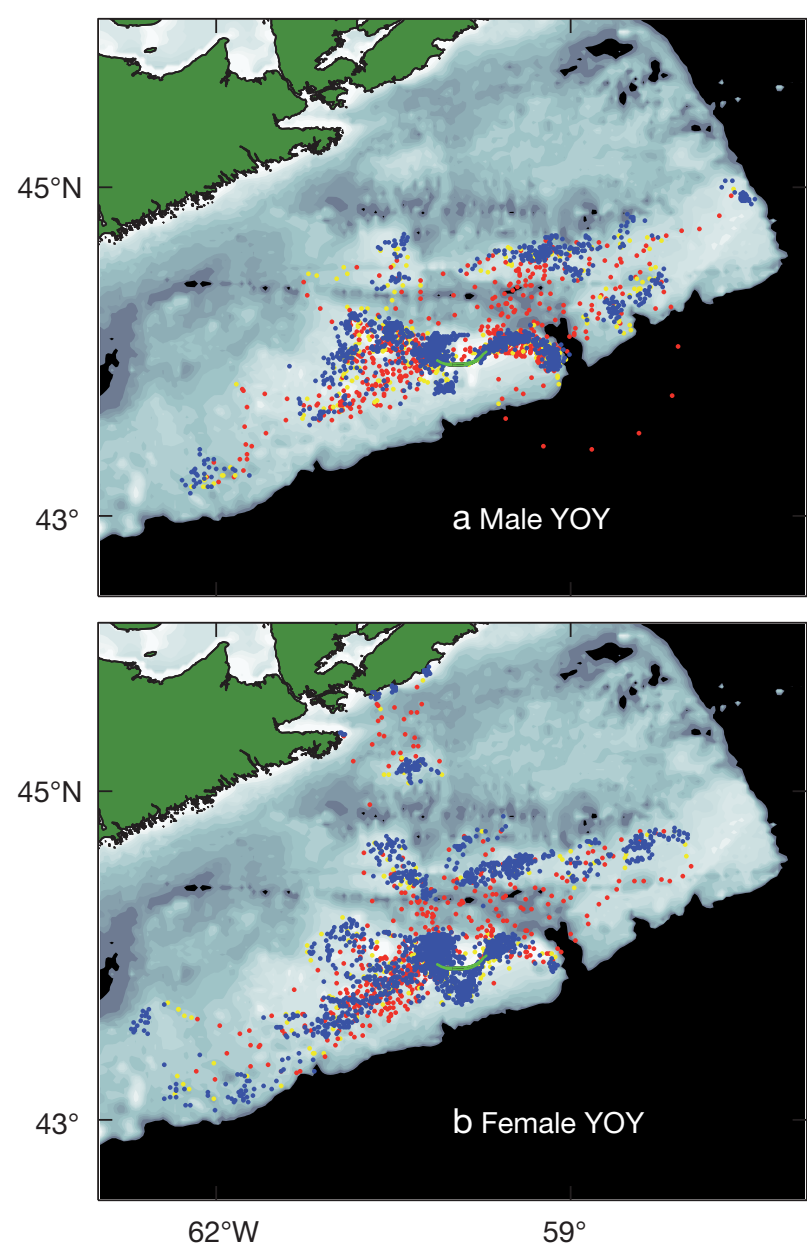

Fig. 2. State-space model-inferred foraging locations for (a) male and (b) female young-of-the-year (YOY). Red: inferred travel locations; blue: foraging; yellow: uncertain. Panels span a subset of the data from October to December 2004 


\section{General fit and appropriateness of the mixed-effects models}

Although the most complex trigonometric wave model had 8 parameters to describe how season affected movement behaviour, the simplest trigonometric model $\left(f_{1}\right)$ had only 2 parameters for season. This simplest model fit seasons as a single annual sine wave, and had a total of only 3 parameters and 2 interaction terms (not including random effect and autocorrelation, which are necessary to prevent overestimation of significance in all the models we fit). In every case except one, the $f_{1}$ model explained more variance as measured by AIC than models using categorical seasons or seasons modelled as polynomials (Table 2). The cubic polynomial model was slightly favoured for travel speed, but because travel speed neither differed between groups nor varied significantly with season in any model (Table 3), it is irrelevant which model had the lowest AIC. Because even the simplest sine wave fit better than categorical seasons or polynomials, we discuss and interpret only those models henceforth.

Though a single sine wave fit better than the categorical or polynomial model, more complex trigonometric models increased explanation over a sine wave, suggesting more complex seasonal patterns of behaviour than a simple oscillation. Mixtures of 3 frequencies (the $f_{1+2+3}$ model) had either the lowest AIC or were coincident with large decreases in AIC compared with the $f_{1+2}$ model for 6 of the 9 trip or habitat measures (distance to shore, water depth, trip length, patch distance, travel time and patch residence). This suggests that 3 peaks occurred in these behaviours throughout the year. In the case of behaviours related to how far foraging occurred from haul-out sites (distance from shore and patch distance), somewhat more support was suggested for the more complex $f_{1+2+3+4}$ model. For water depth, trip length and travel time, both the $f_{1+2+3}$ and $f_{1+2+3+4}$ models are supported over other models, but as $\triangle \mathrm{AIC}$ between the two is small,

Table 2. Akaike's information criterion (AIC) scores for all mixed-effects models comparing differing models of the seasonal effect. Subscripts of $f$ indicate which sine and cosine wave frequencies were included. Seasons: models with categorical seasons; Cubic: models with seasons fit by orthogonal cubic polynomials. The lowest AIC scores are in bold; asterisks denote large drops in AIC with one step up in complexity where seasons were fit with sine and cosine waves. AICs should be interpreted with effect magnitude in mind; ${ }^{* *}$ indicates a significant group or season effect, and in those cases AIC scores are meaningful (see Table 3)

\begin{tabular}{|c|c|c|c|c|c|c|c|}
\hline Response & $f_{1}$ & $f_{1+2}$ & $f_{1+2+3}$ & $f_{1+2+3+3}$ & Seasons & Cubic & Group only \\
\hline Distance to shore $(\mathrm{km})^{* *}$ & 8106.3 & 8096.4 & $7996.6^{*}$ & 7972.4 & 8218.3 & 8119.6 & 8182.1 \\
\hline Water depth $(\mathrm{m})^{* *}$ & 11631.4 & 11643.6 & 11590.6 & 11593.6 & 11653.9 & 11639.3 & 11655.5 \\
\hline Trip length $(\mathrm{d})^{* *}$ & 2793.9 & 2778.7 & 2742.4 & 2742.9 & 2823.0 & 2797.1 & 2824.3 \\
\hline Patch distance $(\mathrm{km})^{* *}$ & 3104.4 & 3105.2 & $3073.8^{*}$ & 3062.2 & 3131.8 & 3110.7 & 3133.7 \\
\hline Foraging ratio** & 6167.3 & 6162.7 & 6170.1 & 6178.3 & 6185.2 & 6177.7 & 6190.3 \\
\hline Patch residence $(\mathrm{d})^{* *}$ & 3969.7 & 3973.9 & 3965.6 & 3975.1 & 3970.5 & 3966.8 & 3974.0 \\
\hline Travel time (d) & 3663.2 & 3676.1 & 3663.9 & 3661.3 & 3681.6 & 3664.0 & 3683.5 \\
\hline Travel speed $\left(\mathrm{km} \mathrm{h}^{-1}\right)$ & 1179.4 & 1187.8 & 1194.6 & 1206.8 & 1182.1 & 1177.5 & 1178.2 \\
\hline Travel tortuosity & 733.1 & 743.5 & 756.2 & 768.5 & 736.2 & 737.9 & 739.1 \\
\hline
\end{tabular}

Table 3. Summary of behavioural differences from linear mixed-effects model results. The columns show the exponentiated model intercept coefficients for the group effect \pm SE (note the $95 \%$ CI of the back-transformed logit in the case of ratios). Group effect indicates the basic pattern of differences between each of the 4 demographic groups (F: adult females; M: adult males; S: subadults; Y: young-of-the-year, YOY), although not all comparisons are shown. Greater or less than signs $(>,<)$ indicate a significant difference and its direction $(\mathrm{p}<0.05)$; equals sign indicates no difference. Where seasonal differences were present, they were highly significant ( $p<0.00001)$ in at least one $\alpha$ (as defined in Eqs $1 \& 2$ ) as indicated by ${ }^{* *}$ in the group effect differences. However, these differences are better represented graphically because of the up to 8 additive $\alpha$ 's and 4 demographic groups to compare (see Figs. 3, 4, 5)

\begin{tabular}{|c|c|c|c|c|c|}
\hline Response variable & Adult males & Adult females & Subadults & YOY & Group effect \\
\hline Distance to shore $(\mathrm{km})$ & $45.1 \pm 4.3$ & $39.6 \pm 5.3$ & $29.9 \pm 7.4$ & $53.8 \pm 8.2$ & $\mathrm{Y}>\mathrm{M}=\mathrm{F}>\mathrm{S}^{* *}$ \\
\hline Water depth (m) & $52.4 \pm 4.0$ & $38.9 \pm 12.9$ & $41.5 \pm 19.1$ & $39.9 \pm 13.7$ & $\mathrm{M}=\mathrm{F}=\mathrm{Y}=\mathrm{S}^{* *}$ \\
\hline Trip length (d) & $7.4 \pm 1.0$ & $6.5 \pm 0.65$ & $5.1 \pm 1.1$ & $8.6 \pm 1.3$ & $\mathrm{Y}>\mathrm{M}=\mathrm{F}>\mathrm{S}^{* *}$ \\
\hline Patch distance $(\mathrm{km})$ & $28.2 \pm 7.0$ & $20.3 \pm 3.6$ & $15.5 \pm 7.15$ & $40.2 \pm 11.0$ & $\mathrm{Y}>\mathrm{M}>\mathrm{F}=\mathrm{S}^{* *}$ \\
\hline Foraging ratio & $0.52(0.39-0.66)$ & $0.85(0.39-0.89)$ & $0.55(0.34-0.75)$ & $0.45(0.31-0.61)$ & $\mathrm{F}>\mathrm{M}=\mathrm{Y}=\mathrm{S}$ \\
\hline Patch residence $(\mathrm{d})$ & $4.3 \pm 0.57$ & $4.1 \pm 0.39$ & $3.0 \pm 0.72$ & $3.9 \pm 0.58$ & $\mathrm{Y}=\mathrm{F}=\mathrm{M}=\mathrm{S}$ \\
\hline Travel time $(\mathrm{d})$ & $0.70 \pm 0.13$ & $0.49 \pm 0.06$ & $0.43 \pm 0.12$ & $0.92 \pm 0.19$ & $\mathrm{Y}>\mathrm{M}>\mathrm{F}=\mathrm{S}^{* *}$ \\
\hline Travel speed $\left(\mathrm{km} \mathrm{h}^{-1}\right)$ & $1.53 \pm 0.18$ & $1.43 \pm 0.12$ & $1.66 \pm 0.34$ & $1.63 \pm 0.19$ & $\mathrm{Y}=\mathrm{F}=\mathrm{M}=\mathrm{S}$ \\
\hline Travel tortuosity & $1.68 \pm 0.25$ & $1.48 \pm 0.15$ & $1.57 \pm 0.44$ & $1.66 \pm 0.23$ & $\mathrm{Y}=\mathrm{F}=\mathrm{M}=\mathrm{S}$ \\
\hline
\end{tabular}



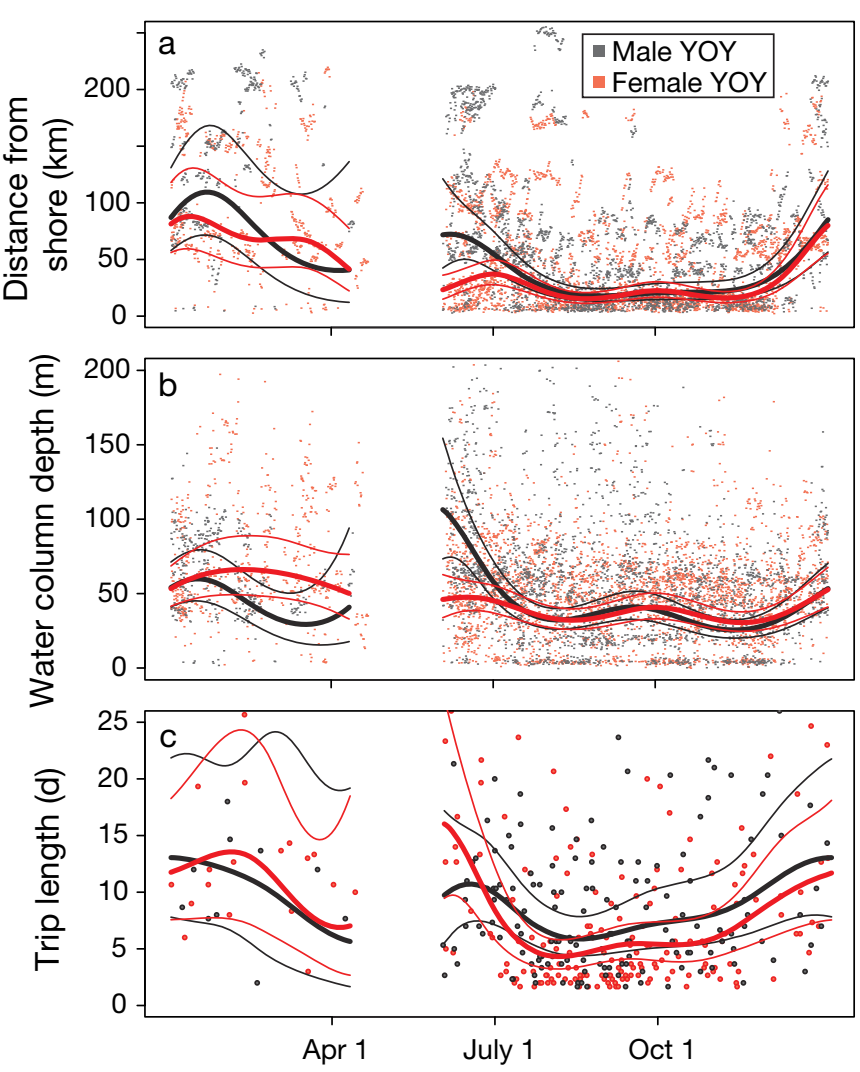

Fig. 3. Mixed-effects estimates and $95 \%$ CI of (a) foraging location distances from shore, (b) water depth at foraging locations and (c) trip length through the year. Sine models explain a significant seasonal pattern. Raw data for each group are plotted as points. There were a small number of minor behavioural differences between the sexes at this age (see Table S2 in the supplement)

the evidence to select one over the other is equivocal (Table 2). Generally, mixtures of 3 wave frequencies best explain the seasonality of movement behaviours, but in some a little more variation was explained by the $f_{1+2+3+4}$ model, as supported by AIC.

\section{Foraging behaviour and age}

Distance from shore of foraging locations

Distance of foraging locations from the nearest landmass differed among YOY, subadults and adults. On average, foraging locations of YOY were farther from shore than those of subadults or adult females, but were similar to adult males. YOY and subadults had similar, nearly identical seasonal patterns, but YOY foraging locations were nearly $20 \mathrm{~km}$ farther from shore than those of subadults in nearly all months (Table 3, Figs. $2 \& 4$ b). Adult seasonal patterns in foraging location distance from shore were more complex than YOY or subadults and contained an extra peak in the fall and a dip coincident with the January breeding season. Seasonal patterns of adult males and adult females also differed significantly, having similar patterns, but with males tending to forage much farther from shore at peak times (Table 3, Fig. 4a).

The seasonal pattern of YOY and subadults included 2 peaks: a large peak in midwinter and a smaller peak in early summer. From midsummer to late fall, YOY and especially subadult foraging locations were close to shore. Foraging locations of YOY and subadults moved away from shorelines much later in the fall than adults, and remained well offshore during the breeding season with no return to haul-out sites during breeding. In addition, the midwinter and early summer peaks may be connected, but the models fit poorly because of sparse data around the spring moult and resulting loss of tags. This possibility is supported by the small difference in AIC scores between the $f_{1}$ and $f_{1+2}$ models when models are fit only to YOY data, suggesting that an annual cycle containing a single peak fits these data almost as well as a mixture of 1 and 2 cycles.

\section{Water depth at foraging locations}

YOY generally foraged in shallower water than other age classes, but there was a high degree of overlap between YOY and adult females in water depth at foraging locations. Subadults foraged somewhat deeper than YOY and adult females, but adult males foraged in the deepest water (Fig. 4c,d). Again, there was a strong seasonal pattern. Although the seasonal pattern is less distinct than distance from shore, depth at foraging locations still generally increased in winter and decreased in summer. YOY and subadults had remarkably similar seasonal patterns (Fig. 4d). Adult seasonal patterns in water depth were similar to YOY and subadult patterns, except the increase in depth over the fall and winter was interrupted by a return to shallow water during the breeding season. All adults, but especially adult males, used deeper water than YOY or subadults immediately before and after the breeding season (Fig. 4c).

\section{Trip structure}

The seasonal patterns evident in habitat properties were also reflected in foraging trip structure. However, mixed-effects fits to trip properties had larger confidence intervals, and differences were harder to detect. This was because a trip accounted for a single observation, but it could contain dozens of foraging locations, which reduced the effective sample size relative to the habitat models. Nonetheless, significant seasonal and 

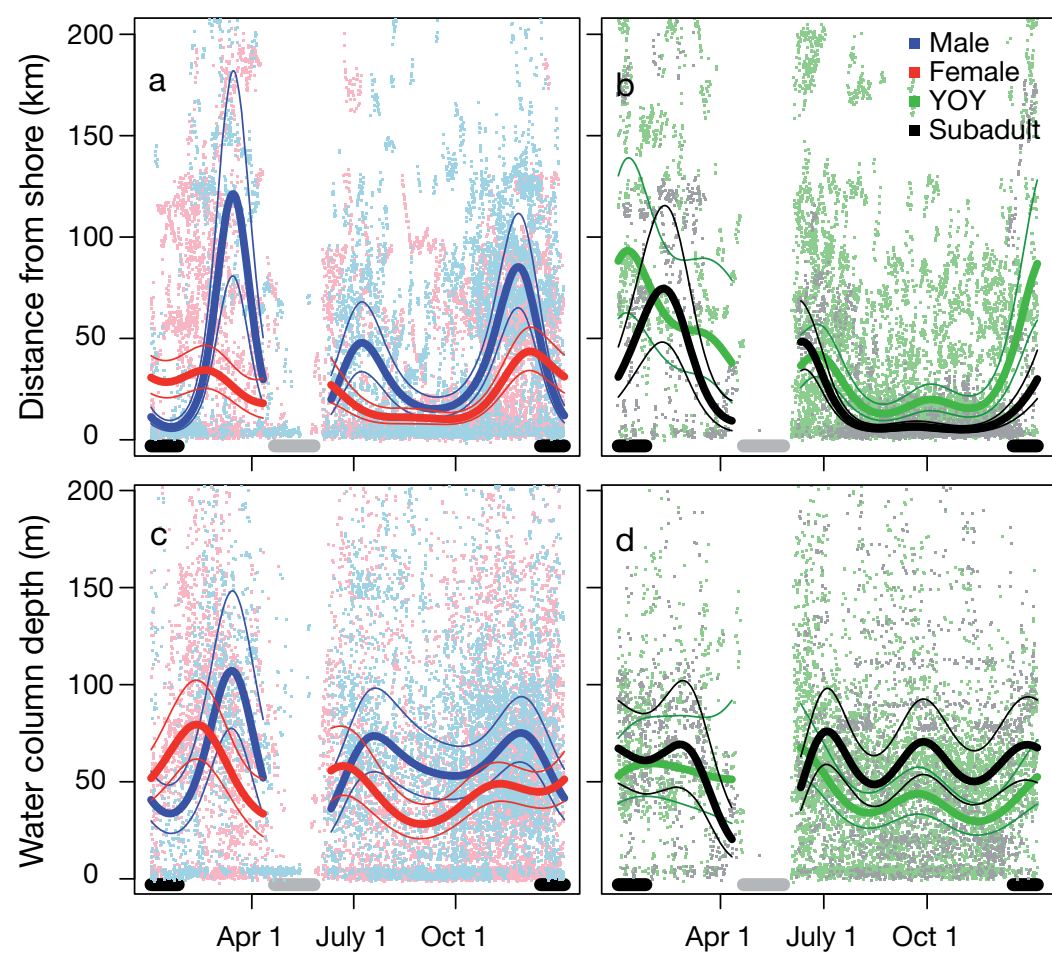

Fig. 4. Mixed-effects model fits and 95\% CI for (a,b) foraging location distance from shore and $(\mathrm{c}, \mathrm{d})$ water depth for each demographic group. Raw data for each group are plotted as points. Black horizontal bars along the $x$-axis indicate the dates of the breeding season; grey bars indicate the moult period. YOY: youngof-the-year

demographic differences were present in many trip attributes.

YOY, subadults and adults structured trips differently. The back-transformed (exponentiated) model-fit annual mean trip length was $8.6 \mathrm{~d}$ for YOY, approximately $3 \mathrm{~d}$ longer than subadult trips, $2 \mathrm{~d}$ longer than adult female trips and $1 \mathrm{~d}$ longer than adult male trips (Table 3). Superimposed on these annual means were differing seasonal cycles. YOY and subadults had similar seasonal patterns, with shorter trips in the summer and longer trips in the winter, but YOY made longer trips than subadults in all seasons (Fig. 5b). Adults made short trips during summer and long trips during winter, but had a period of short trips at the peak of the breeding season.

Just before and just after the January breeding season, adults, especially males, made very long trips, considerably longer than YOY or subadults (Fig. 5a). Relative to other groups, YOY consistently made intermediate to long trips year-round, and although older groups occasionally made long or very long trips at particular times of year, older animals normally made short or intermediate length trips.

For all groups, trips involved more travel during winter and less travel in summer. On average, YOY trips had the lowest foraging ratio (more time travelling, less foraging) of any group, whereas adult females had the highest. Like other behavioural metrics, group differences in this ratio showed strong seasonality (Fig. 5c,d).

\section{Navigation}

Travel tortuosity and, to a lesser extent, travel speed were used as measures of navigation ability. There were no differences in these characteristics between YOY, subadults, and adults. Travel tortuosities were similar for all groups, averaging between 1.48 and 1.68, with no significant seasonality detected in any group (Table 3). Similarly, travel speed was not seasonal and did not differ among groups, ranging from 1.43 to $1.68 \mathrm{~km} \mathrm{~h}^{-1}$ (Table 3 ).

\section{DISCUSSION}

All animals must employ foraging strategies that integrate across spatial and temporal patchiness to meet current and future energy demands while minimising predation risk and physiological stress (McNamara \& Houston 1986). In seasonal environments, foraging strategies would be expected to change seasonality and be nested in an annual routine (McNamara \& Houston 2008). In this population, we found strong evidence for state-specific annual routines, as foraging behaviour and foraging trip organisation differed markedly among YOY, subadult and adult grey seals and exhibited complex stage-specific seasonal movement and foraging patterns.

\section{Differences between male and female YOY}

In sexually size-dimorphic species, size is thought to drive many observed behavioural differences (LeBoeuf et al. 2000, Ruckstuhl \& Neuhaus 2005, Lewis et al. 2006). In most known examples, behavioural differences are minimal or nonexistent at birth and manifest later as one sex grows larger than the other (Shine 1989, 1991, Ruckstuhl \& Neuhaus 2005). Our results are mostly consistent with this pattern, but the small differences we observed between male and female YOY (deeper foraging in summer by males than females, less overall inferred 'foraging' state and 


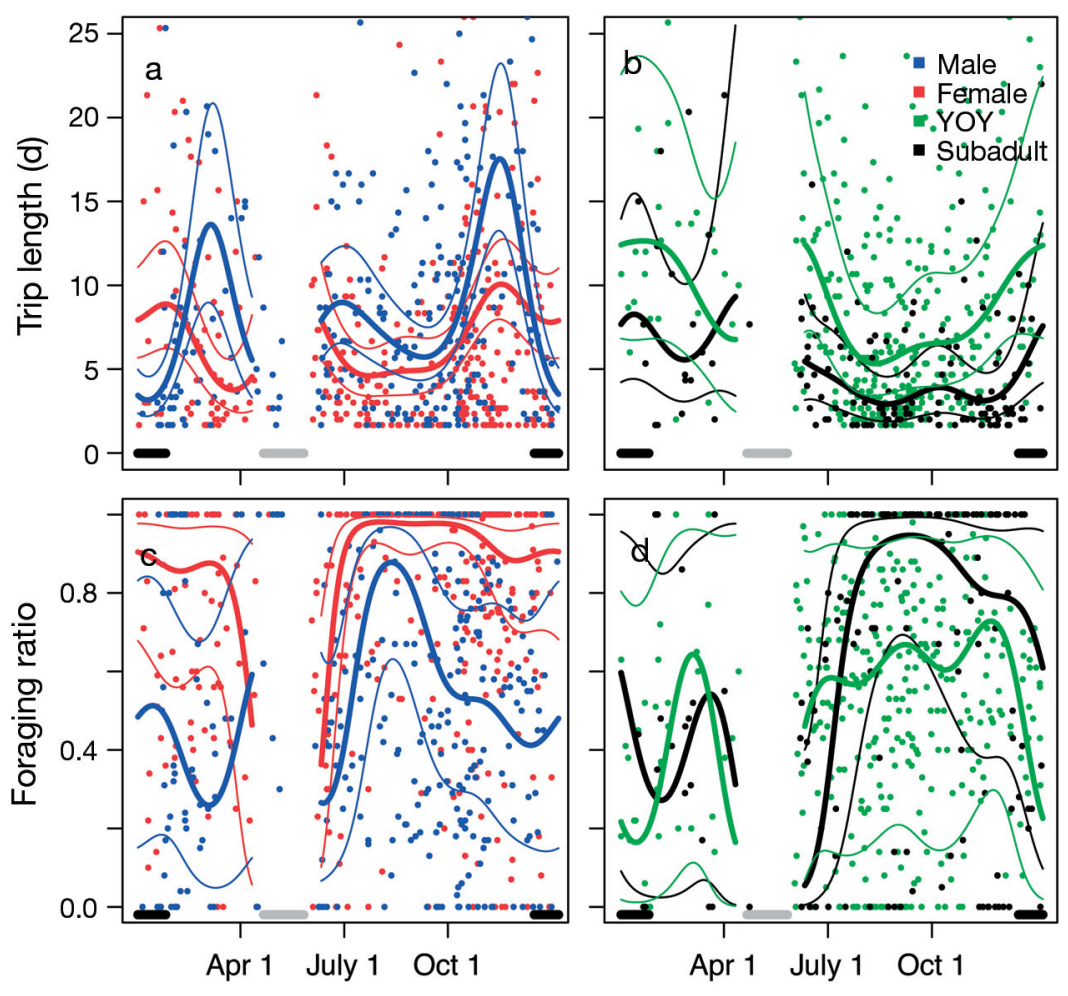

Fig. 5. Mixed-effects model fits and 95\% CI for (a,b) trip length and (c,d) foraging ratio for each demographic group. Foraging ratios show wide confidence intervals due to the logit transform, but a seasonal pattern of higher foraging relative to travel in the summer and lower foraging relative to travel in the winter, is consistent with other behavioural and habitat measures. YOY trip lengths are generally longer than other demographic groups, though trip lengths of adult males peak much higher than those of YOY just before and after the breeding season. Black horizontal bars along the $x$-axis indicate the dates of the breeding season; grey bars indicate the moult period. Raw data for each group are plotted as points. YOY: young-of-the-year

shorter winter patch residence in males than females) are consistent with differences observed between the sexes later in life. In this population, there is little sexual differential in size at birth, weaning or $1 \mathrm{yr}$ of age (Anderson \& Fedak 1987, Bowen et al. 1992, 2006, W. D. Bowen et al. unpubl. data). Since the sexes differ little in size at this age, our results suggest that the sexrelated behavioural differences observed in adults (Beck et al. 2003c, Breed et al. 2006, 2009) are expressed very early in life before significant sexual size dimorphism is apparent. As such, size differential alone cannot explain behavioural differences; other ontogenetic factors must play some role.

There is evidence of sex-specific mortality of YOY in British grey seals, with males showing a much higher mortality rate than females (Hall et al. 2001). Although we have no estimates of YOY mortality from this population, if there is increased mortality in male YOY, it may be the result of sex-specific foraging or movement behaviours.

\section{Foraging effort and age}

Accounting for seasonality, there are important mean behavioural differences among YOY, subadults and adults. Most notably, YOY foraging effort is generally elevated compared with other age classes, i.e. they make longer foraging trips to forage farther from haul-out than older animals. Since they are apparently working harder, but do not accumulate blubber, foraging trips made by YOY must be less efficient. It is not clear why they are foraging farther from shore, but intraspecific competition for more accessible habitat closer to shore may be keen, and YOY may be losing in this competition (Matthiopoulos 2003). It is also possible that the small size of YOY causes them to target smaller prey, which have reduced profitability per capture, and this might account for longer trips. Where found in other species, elevated foraging effort by juveniles is almost always due to ineffective foraging behaviours (Marchetti \& Price 1989, Heinsohn 1991, Wunderle 1991, Vanderhoff \& Eason 2007), and this is very likely an important factor in this case.

Diet data also suggest an overall lessefficient foraging strategy in YOY grey seals. YOY up to 6 mo old had a wide dietary breadth, while adults, especially females, were often highly individually specialised on just 1 or 2 prey species (Beck et al. 2007, Tucker et al. 2007). Generalist strategies are usually less efficient than specialist strategies, particularly in competitive environments or where different prey items require different capture and handling strategies (Stephens \& Krebs 1986, Estes et al. 2003).

Inexperience is not the only possible explanation. If high enough, metabolic rate in YOY could explain higher effort levels. YOY do have a higher mass-specific metabolic rate, but metabolic rate scales with size and not age. Subadults should have only a slightly lower metabolic rate than YOY, but their behaviour suggests markedly lower foraging effort that cannot be explained by the predicted small difference in metabolic rate (Sparling \& Fedak 2004). Foraging behaviour of YOY is likely also affected by their lower ability to store oxygen (Noren et al. 2005), which prevents them from diving as deep as older animals (G. A. Breed et al. unpubl. data). This limitation might otherwise force YOY to forage in the water column rather than at the bottom. However, 
fatty acid profiles suggest that YOY forage almost exclusively on benthic and demersal species (Beck et al. 2007). Reduced diving ability would thus restrict YOY to shallower areas than adults, resulting in less overall habitat available for YOY (Keddy 2001).

\section{Navigation}

Foragers do not have perfect knowledge of their environment from which to anticipate future resources, and the level of knowledge is likely to differ across age classes. Young animals are presumed to have little or no knowledge of food resource distribution, predation risk, competition or prey handling techniques. Thus, we expected YOY to initially navigate poorly compared with adults but improve over the course of their first year as they gained experience. However, if there were differences in navigation ability between YOY and adults, they were not reflected in tortuosity of travel or travel speed. These are not the strongest tests of navigation ability, but they do indicate that YOY are proficient at getting to and from foraging areas.

In addition, there were no seasonal patterns in travel speed or tortuosity, suggesting that all age classes, including YOY, quickly adjusted their foraging patterns as prey fields changed. Other young or naive animals have been shown to adjust search and foraging strategies quickly as they sample resources in the environment (e.g. Greggers \& Menzel 1993, Sutherland \& Gass 1995, Winter \& Stich 2005). In this population, however, YOY are almost certainly not as proficient as adults at foraging, as evidenced by their need to make longer foraging trips. This suggests that YOY have no problem locating, navigating to or following migrations of prey, but take more time to capture and handle prey than adults. To definitively test this hypothesis in this population, however, would require camera or other direct observation of prey capture attempts and success.

\section{Annual foraging routines}

Prominent annual cycles in trip structure and habitat use were evident in all age classes and suggest a summer nadir and winter peak in foraging effort. Beck et al. $(2003 \mathrm{~b}, \mathrm{c})$ detected similar patterns in adult diving behaviour (see Fig. 5 in Beck et al. 2003c). They surmised that decreased foraging effort during summer was due to timing lipid accumulation to support the energetic costs of reproduction, because too much blubber during the summer had negative fitness consequences (Beck et al. 2003a). The more complex annual foraging patterns of adults, particularly the increased apparent foraging effort a month earlier in the autumn than YOY or subadults, does suggest that energetic investments for reproduction do greatly affect foraging behaviour. However, our results show that YOY and subadults had the same general pattern of lowered summer and increased winter foraging effort as reproductive adults. These young animals are growing somatically and are extremely lean (Trzcinski et al. 2006). Avoiding too much blubber cannot explain seasonal foraging patterns in these young animals.

Increased foraging effort during winter is coincident with winter fish migration to deeper, offshore waters. Conversely, decreased summer effort occurs when many prey move into shallower nearshore waters and the tops of banks (Perry \& Smith 1994, Swain et al. 1998). Prey species also show pronounced annual cycles in energy density, becoming lipid rich in the summer prior to spawning and losing condition through the winter. Thus, the same prey items in winter will have less energy than they do in the summer (Smigielski et al. 1984, Comeau et al. 2002, Beck et al. 2007). In addition to changes in energy density and depth distribution, some prey such as sandlance, a major component of the diet, spend more time hidden in sand (Smigielski et al. 1984), requiring predators to switch foraging tactics.

\section{Conclusions}

Here we show that YOY and subadult grey seals behave differently than adults while at sea. Although some of these differences might have been predicted from differential size and experience, these effects interacted with a seasonally dynamic environment to produce unexpected stage-specific patterns of foraging effort. Many ecosystems, including the Scotian Shelf (Frank et al. 2005), have experienced major trophic structure changes. The small details of a predator's life history, such as those uncovered in this and related studies (Beck et al. 2003a, 2007), may serve to concentrate the top-down effects onto particular prey species or diffuse them across many trophic levels (Polis \& Strong 1996, Estes et al. 1998, Ripple \& Beschta 2004). Subadults and YOY account for $52 \%$ of the standing biomass in this population (Trzcinski et al. 2006), and understanding age-specific foraging behaviour and trophic interactions may prove no less important to overall ecosystem structure than understanding the drivers of primary production. Grey seals are undoubtedly an extremely important marine predator in this ecosystem, and the effects of their foraging likely ripple across the Scotian Shelf, just as the life histories of other top predators ripple through ecosystems, marine and terrestrial, worldwide. 
Acknowledgements. This work would not have been possible without contributions from a number of people. Most importantly, we thank R. Myers for his tireless dedication to science and conservation and his generous academic and financial support. We also thank I. D. Jonsen and W. Blanchard who offered considerable help with statistical analysis and modelling. M. Lewis, I. D. Jonsen, T. Patterson, F. S. Dobson and anonymous reviewers provided very helpful comments to earlier drafts of this work. S. Iverson, S. Lang, D. Lidgard and J. McMillian provided help in the field. This work was supported by the Future of Marine Animal Populations program, Fisheries and Oceans Canada, Dalhousie University and NSERC grants awarded to M.L.L. and W.D.B. This research was conducted under the authorization of the Canadian Ministry of Fisheries protocol nos. 04-13, 02-91, 00-051 and 98-078.

\section{LITERATURE CITED}

Anderson S, Fedak M (1987) Grey seal, Halichoerus grypus, energetics: females invest more in male offspring. J Zool 211:667-679

Austin D, McMillan JI, Bowen WD (2003) A three-stage algorithm for correcting ARGOS satellite locations. Mar Mamm Sci 19:371-383

Austin DA, Bowen WD, McMillan JI (2004) Intraspecific variation in movement patterns: modeling individual behaviour in a large marine predator. Oikos 105:15-30

- Austin D, Bowen W, McMillan J, Boness D (2006) Stomach temperature telemetry reveals temporal patterns of foraging success in a free-ranging marine mammal. J Anim Ecol 75:408-420

Baker JD (2007) Post-weaning migration of northern fur seal Callorhinus ursinus pups from the Pribilof Islands, Alaska. Mar Ecol Prog Ser 341:243-255

Beck CA, Bowen WD, Iverson SJ (2003a) Sex differences in the seasonal patterns of energy storage and expenditure in a phocid seal. J Anim Ecol 72:280-291

Beck CA, Bowen WD, McMillan JI (2003b) Sex differences in diving at multiple temporal scales in a size-dimorphic capital breeder. J Anim Ecol 72:979-993

Beck CA, Bowen WD, McMillan JI, Iverson SJ (2003c) Sex differences in the diving behaviour of a size-dimorphic capital breeder: the grey seal. Anim Behav 66:777-789

Beck CA, Iverson SJ, Bowen WD, Blanchard W (2007) Sex differences in diet reflect seasonal variation in foraging behaviour and energy balance: evidence from quantitative fatty acid signature analysis. J Anim Ecol 76:490-502

Bowen WD, Stobo WT, Smith SJ (1992) Mass changes of grey seal (Halichoerus grypus) pups on Sable Island: differential maternal investment reconsidered. J Zool 227:607-672

Bowen WD, Iverson SJ, McMillan JI, Boness DJ (2006) Reproductive performance in grey seals: age-related improvement and senescence in a capital breeder. J Anim Ecol 75: 1340-1351

Breed GA, Bowen WD, McMillan JI, Leonard ML (2006) Sexual segregation of seasonal foraging habitats in a nonmigratory marine mammal. Proc R Soc Lond B Biol Sci 273:2319-2326

Breed GA, Jonsen ID, Myers RA, Bowen WD, Leonard ML (2009) Sex-specific, seasonal foraging tactics of adult grey seals (Halichoerus grypus) revealed by state-space analysis. Ecology 90:3209-3221

Breed GA, Costa DP, Goebel ME, Robinson PW (2011) Electronic tracking tag programming is critical to data collection for behavioral time-series analysis. Ecosphere 2:art10
Clutton-Brock T, Godfray C (1991) Parental investment. In: Krebs J, Davies N (eds) Behavioural ecology: an evolutionary approach, 3rd edn. Blackwell Scientific Publications, Oxford, p 234-262

- Comeau L, Campana S, Chouinard G (2002) Timing of Atlantic cod (Gadus morhua L.) seasonal migrations in the southern Gulf of St. Lawrence: interannual variability and proximate control. ICES J Mar Sci 59:333

Estes JA, Tinker MT, Williams TM, Doak DF (1998) Killer whale predation on sea otters linking oceanic and nearshore ecosystems. Science 282:473-476

Estes J, Riedman M, Staedler M, Tinker M, Lyon B (2003) Individual variation in prey selection by sea otters: patterns, causes and implications. J Anim Ecol 72:144-155

Field IC, Bradshaw CJA, Burton HR, Sumner MD, Hindell MA (2005) Resource partitioning through oceanic segregation of foraging juvenile southern elephant seals (Mirounga leonina). Oecologia 142:127-135

Frank KT, Petrie B, Choi JS, Leggett WC (2005) Trophic cascades in a formerly cod-dominated ecosystem. Science 308:1621

> Greggers U, Menzel R (1993) Memory dynamics and foraging strategies of honeybees. Behav Ecol Sociobiol 32:17-29

Hall AJ, McConnell BJ, Barker RJ (2001) Factors affecting first-year survival in grey seals and their implications for life history strategy. J Anim Ecol 70:138-149

Harrell F (2001) Regression modeling strategies: with applications to linear models, logistic regression, and survival analysis. Springer Verlag, New York, NY

> Heinsohn R (1991) Slow learning of foraging skills and extended parental care in cooperatively breeding whitewinged choughs. Am Nat 137:864-881

Holm S (1979) A simple sequentially rejective multiple test procedure. Scand J Stat 6:65-70

Jonsen ID, Mills Flemming J, Myers RA (2005) Robust statespace modeling of animal movement data. Ecology 86: $2874-2880$

Jonsen ID, Myers RA, James MC (2007) Identifying leatherback turtle foraging behaviour from satellite telemetry using a switching state-space model. Mar Ecol Prog Ser 337:255-264

Keddy PA (2001) Competition. Kluwer Acedemic Publishers, Dordrecht

LeBoeuf BJ, Crocker DE, Costa DP, Blackwell SB, Webb PM, Houser DS (2000) Foraging ecology of northern elephant seals. Ecol Monogr 70:353-382

Lewis R, O'Connell T, Lewis M, Carnpagna C, Hoelzel A (2006) Sex-specific foraging strategies and resource partitioning in the southern elephant seal (Mirounga leonina). Proc R Soc Lond B Biol Sci 273:2901-2907

Marchetti K, Price T (1989) Differences in the foraging of juvenile and adult birds: the importance of developmental constraints. Biol Rev Camb Philos Soc 64:51-70

> Matthiopoulos J (2003) Model-supervised kernel smoothing for the estimation of spatial usage. Oikos 102:367-377

- McConnell B, Fedak M, Burton H, Engelhard G, Reijnders P (2002) Movements and foraging areas of naive, recently weaned southern elephant seal pups. J Anim Ecol 71:65-78

> McNamara J, Houston A (1986) The common currency for behavioral decisions. Am Nat 127:358-378

- McNamara J, Houston A (2008) Optimal annual routines: behaviour in the context of physiology and ecology. Philos Trans R Soc Lond B 363:301

- Noren SR, Iverson SJ, Boness DJ (2005) Development of the blood and muscle oxygen stores in gray seals (Halichoerus grypus): implications for juvenile diving capacity and the necessity of a terrestrial postweaning fast. Physiol Bio- 
chem Zool 78:482-490

Patterson TA, Thomas L, Wilcox C, Ovaskainen O, Matthiopoulos J (2008) State-space models of individual animal movement. Trends Ecol Evol 23:87-94

Perry R, Smith S (1994) Identifying habitat associations of marine fishes using survey data: an application to the northwest Atlantic. Can J Fish Aquat Sci 51:589-602

Pinheiro J, Bates D, DebRoy S, Sarkar D, R Development Core Team (2009) nlme: linear and nonlinear mixed effects models. R Foundation for Statistical Computing, Vienna. Available at www.R-project.org

Polis G, Strong D (1996) Food web complexity and community dynamics. Am Nat 147:813

R Development Core Team (2008) R: a language and environment for statistical computing. R Foundation for Statistical Computing, Vienna. Available at www.R-project.org

Raum-Suryan K, Rehberg M, Pendleton G, Pitcher K, Gelatt T (2004) Development of dispersal, movement patterns, and haul-out use by pup and juvenile steller sea lions (Eumetopias jubatus) in Alaska. Mar Mamm Sci 20:823-850

Ripple W, Beschta R (2004) Wolves and the ecology of fear: Can predation risk structure ecosystems? Bioscience 54: 755-766

Ruckstuhl K, Neuhaus P (2005) Sexual segregation in vertebrates: ecology of the two sexes. Cambridge University Press, Cambridge

Sandwell DT, Smith WHF (1992) Global marine gravity from ERS-1, Geosat and Seasat reveals new tectonic fabric. Eos Trans AGU 73:133

Schick RS, Loarie SR, Colchero F, Best BD and others (2008) Understanding movement data and movement processes: current and emerging directions. Ecol Lett 11:1338-1350

Schwarz C, Stobo W (2000) Estimation of juvenile survival, adult survival, and age-specific pupping probabilities for the female grey seal (Halichoerus gryprus) on Sable Island from capture-recapture data. Can J Fish Aquat Sci 57: $247-253$

Service Argos (2009) Argos user's manual. Collecte Localisation Satellites, Ramonville Saint-Agne

Shine R (1989) Ecological causes for the evolution of sexual dimorphism: a review of the evidence. Q Rev Biol 64: 419-461

Editorial responsibility: Steve Dawson,

Dunedin, New Zealand
Shine R (1991) Intersexual dietary divergence and the evolution of sexual dimorphism in snakes. Am Nat 138:103-122

Smigielski AS, Halavik TA, Buckley LJ, Drew SM, Laurence GC (1984) Spawning, embryo development and growth of the American sand lance Ammodytes americanus in the laboratory. Mar Ecol Prog Ser 14:287-292

Sparling CE, Fedak MA (2004) Metabolic rates of captive grey seals during voluntary diving. J Exp Biol 207: 1615-1624

Stephens DW, Krebs JR (1986) Foraging theory. Princeton University Press, Princeton, NJ

Sutherland G, Gass C (1995) Learning and remembering of spatial patterns by hummingbirds. Anim Behav 50: $1273-1286$

Swain D, Chouinard G, Morin R, Drinkwater K (1998) Seasonal variation in the habitat associations of Atlantic cod (Gadus morhua) and American plaice (Hippoglossoides platessoides) from the southern Gulf of St. Lawrence. Can J Fish Aquat Sci 55:2548-2561

> Trzcinski MK, Mohn R, Bowen WD (2006) Continued decline of the threatened Eastern Scotian Shelf Atlantic cod population: How important is grey seal predation? Ecol Appl 16:2276-2292

Tucker S, Bowen WD, Iverson SJ (2007) Dimensions of diet segregation in grey seals Halichoerus grypus revealed through stable isotopes of carbon $\left(\delta^{13} \mathrm{C}\right)$ and nitrogen $\left(\delta^{15} \mathrm{~N}\right)$. Mar Ecol Prog Ser 339:271-282

Vanderhoff E, Eason P (2007) Disparity between adult and juvenile american robins Turdus migratorius foraging for ground invertebrates and cherry fruits. Ethology 113: 1212-1218

> Vincent C, McConnell BJ, Ridoux V, Fedak MA (2002) Assessment of argos location accuracy from satellite tags deployed on captive gray seals. Mar Mamm Sci 18:156-166

Winter Y, Stich K (2005) Foraging in a complex naturalistic environment: capacity of spatial working memory in flower bats. J Exp Biol 208:539-548

Wunderle J Jr (1991) Age-specific foraging proficiency in birds. Curr Ornithol 8:273-324

Zollner PA, Lima SL (1999) Search strategies for landscapelevel interpatch movements. Ecology 80:1019-1030

Submitted: June 22, 2010; Accepted: March 18, 2011

Proofs received from author(s): May 18, 2011 